\title{
ON THE PERIODIC CHANGE OF THE LUMINOSITY OF THE COSMIC SOURCES WITH AN ACTIVE MEDIUM
}

\author{
Vitaly V. Kostenko, (D)Volodymyr M. Kuklin*, (D)Eugen V. Poklonskiy \\ V.N. Karazin Kharkiv National University, Kharkiv, Ukraine \\ Svobody Sq. 4, Kharkiv, Ukraine, 61022 \\ *Corresponding Author: kuklinvm1@gmail.com \\ Received March 22, 2020; accepted March 27, 2020
}

\begin{abstract}
The presence of an internal layer with an active medium in a hot radiation source is considered, which can be described by a quantum two-level system located near equilibrium. The population of the upper and lower levels is approximately equal. It is shown that during convection from deeper hot layers, which supports the inversion of the populations of the active system, generation of induced radiation pulses is possible, the intensity of which is comparable to or greater than the intensity of the background spontaneous radiation of the source. With a sufficient thickness of the surface layers due to the effects of radiation scattering in them, the emission spectrum of a completely black body may well form there. Pulse generation near a previously detected new threshold of induced radiation can lead to a periodic change in the radiation intensity of the source as a whole. This threshold is determined by the equality of the squared population inversion to the total number of states. The generation of pulses of induced radiation is considered both in Einstein's representation, on the basis of balanced equations, and using a semiclassical description for small values of population inversion and for low levels of electric field intensity, when the Rabi frequency is less than the line width. The description of the induced radiation process is reduced to a one-parameter system of equations. Periodic solutions are represented by closed trajectories on the phase plane (relative density of quanta, relative density of population inversion). A similar layer with an active medium, which can be described by a quantum two-level system located near equilibrium, can exist in stars and is most likely localized in the photosphere. If there is significant convection in the star's atmosphere, conditions can be realized for generating pulses of induced radiation. It turns out that one can see the similarity of the obtained solutions with known observations of changes in the luminosity of Cepheid stars (Cepheus delta and the North Star).
\end{abstract}

KEYWORDS: pulse generation of induced radiation, convective source of population inversion, periodic change in the luminosity of Cepheid stars.

Spontaneous and induced radiation. In the most general case, particle radiation can be either spontaneous, independent of external influence, or stimulated, imposed by an intense external field [1,2]. Consider a particle that has its own field. If this field or part of it is not able to propagate independently of the particle, accompany the particle, then there is no radiation. If, however, during particle motion, translational or vibrational, the particle field is considered, then under certain conditions there will be a part in it that will be able to propagate independently in the medium. The work of this part of the field on the particle will not be zero and will lead to its deceleration or to a decrease in the amplitude of the oscillations, respectively, which is a sign of the presence of radiation of field energy by the particle [3].

It is also important to note that the value of the work of the particle's own field on its own current is always signdefined and describes only the radiation process, which is one of the important characteristic features of spontaneous processes. Another characteristic feature of spontaneous emission is the fact that its sources are independent and the radiation process is not imposed by a wave at this frequency existing in a given medium or system [4].

The induced radiation is due to the fact that an external field in the entire interaction space modulates the movement of particles of the medium. In this case, radiation (or absorption) of many particles located at different points in space may well occur in phase with this field. Ch. H. Townes drew attention to this in his Nobel lecture: “... the energy emitted by molecular systems has the same field distribution and the same frequency as the inducing radiation, and, consequently, a constant (possibly zero) difference phases" [5]. Such radiation synchronized by an external field, as well as particle absorption, leads to a sharp increase in the efficiency of interaction between particles and the field. The cause of the induced (stimulated) radiation, as it turned out, is the presence of population inversion (a positive definite difference of particles at higher and lower energy levels) [1].

Formulation of the problem. Consider the radiation source and select in it the layer where the medium is located, capable of generating periodic radiation pulses.

For example, such a layer in stars can be localized in the region of the photosphere. In some cases, there may be several such layers. It is possible to simulate the active zone of this layer by a two-level quantum system, and the populations of these two levels will be considered approximately equal. With a very insignificant excess of the upper level population (the population inversion is positive in this case), in addition to spontaneous emission, the generation of induced radiation is possible, the threshold of which was found in [6,7]. With a sufficient thickness of the overlying layers due to the effects of scattering of radiation emanating from the active zone of the two-level system in them, the emission spectrum of a completely black body may well form there [8].

In addition, we will assume the existence of strong convective flows emanating from layers closer to the hot region of the source of the source, which are capable of introducing a certain fraction of excited atoms of this active substance into the active zone. That is, such convective flows are able to increase the population inversion in the core. C) V.V. Kostenko, V.M. Kuklin, E.V. Poklonskiy, 2020 
One can verify that the intensity of the induced radiation of a given spectral line, described by a two-level system, can significantly exceed not only the spontaneous intensity of atoms of a given substance, but also the spontaneous emission of the entire spherical source as a whole.

The purpose of this work is to consider the generation of periodic pulses of induced radiation in a heated gas with a fraction of active particles in two states (two-level system). It is important that in a certain active zone of the radiation source, the number of active particles at two energy levels is approximately equal, the population inversion is much less than the total number of particles. Under these conditions, the intensity of the induced radiation is comparable to the intensity of spontaneous emission. It is assumed that in this active zone, which is transparent to radiation at the frequency of the energy transition, due to convection, active particles from the underlying dense layers enter the excited state. That is, in the core there is a source of inverted (excited) active particles.

\section{MODEL OF PULSES GENERATION IN EINSTEIN REPRESENTATIONS}

According to the ideas of A. Einstein, the description of the simplest one-dimensional two-level system in the presence of radiation at the transition frequency using the so-called balance equations is as follows [1]:

$$
\begin{gathered}
\partial n_{2} / \partial t=-u_{21} \cdot n_{2}-w_{21} \cdot \mu \cdot N_{k}, \\
\partial n_{1} / \partial t=u_{21} \cdot n_{2}-w_{12} \cdot \mu \cdot N_{k},
\end{gathered}
$$

moreover, the total number of particles of the system in the first and second levels is constant $N=n_{2}+n_{1}=$ Const,$u_{21}-$ is the rate of change in the number of quanta of the second excited level due to spontaneous emission processes, $\mu=n_{2}-n_{1}$ - is the population inversion. The rate of change in the number of quanta (particles) at these levels due to the induced processes of radiation $w_{21} \cdot N_{k} \cdot n_{2}$ and absorption $w_{12} \cdot N_{k} \cdot n_{1}$. Here $N_{k}$ is the number of radiation quanta (spectral density) at the transition frequency, for which the equation

$$
\partial N_{k} / \partial t=-\delta_{D} N_{k}+u_{21} \cdot n_{2}+w_{21} \cdot \mu \cdot N_{k}
$$

where $\delta_{D}-$ is the decrement of absorption (or radiation loss) of quantum energy. Generally speaking, the relationship between the coefficients $u_{21}$ and $w_{21}$ in the general case can be represented as follows

$$
\frac{u_{21}}{w_{21}}=g=\frac{A_{21}}{\hbar \omega \cdot B_{21}}=\frac{2 \omega^{2}}{\pi c^{3}},
$$

where $A_{21}$ and $B_{21}$ are the corresponding Einstein coefficients. The dimension of this ratio in the three-dimensional case is time per unit volume, since we are talking about the spectral density of quanta. For yellow light the numerical value $g \approx 0.25$, for violet at the edge of the visible spectrum $g \approx 0.6$.

The traditional idea of the instability threshold in neglecting spontaneous processes meets the requirement of positivity of the right-hand side of (3) or, what is the same

$$
\mu=\mu_{T H 1}=\delta_{D} / w_{21}
$$

One can detect the threshold for the appearance of such radiation due to competition with spontaneous processes at a certain critical value of population inversion $\mu_{T H 2}[6,7]$. In the absence of absorption of quantum energy $\left(\delta_{D}=0\right)$, the new threshold for the generation of induced radiation is determined by the relation

$$
\mu=\mu_{T H 2} \approx(2 N)^{1 / 2}=\left[2\left(n_{2}+n_{1}\right)\right]^{1 / 2} .
$$

Near this threshold $n_{2} \geq n_{1} \approx N / 2$, the inversion value $\mu<<n_{2}, n_{1}$ is very small. It is important to note that under these conditions the induced radiation is comparable to spontaneous. Collisions with fast electrons of the medium can provide a transition from the lower energy level of the quantum system to the upper energy level:

$$
\partial \mu / w_{21} \partial t=2\left[\left(v-u_{21}\right) / w_{21}\right] \cdot n_{1}-2 \mu \cdot N_{k}
$$

where $v$ is the effective frequency of collisions with fast electrons of the medium and $n_{2} \approx n_{1} \approx N / 2$. In this case $v \approx u_{21}$ , we can introduce into consideration the quantity

$$
2\left[\left(v-u_{21}\right) / w_{21}\right] \cdot n_{1}=\mu_{0}^{2} I_{0}
$$

where $\mu_{0}=\mu(t=0)$ is some initial population inversion value that exceeds the threshold (6).

The condition $I_{0}=0$ describes the equilibrium state of collisional excitation by free electrons of the main gas of active atoms and their radiative relaxation (due to spontaneous emission). A transition from a higher nonradiative level 
(in this case $v \cdot n_{1} \approx u_{32} \cdot n_{3}$ ) can take an active part in the excitation of the upper working level, then a dark line (absorption line at the frequency of this transition) appears in the spectrum, which allows one to determine the sort of particles and the working levels of the quantum system.

Under the discussed conditions, at various levels of initial inversion both near the threshold (6) and far from it, equations (3), (7) are similar to the Statz-DeMars equations [9], which describe relaxation (that is, damped) oscillations with the establishment of a stationary state. The situation changes if transfer of population inversion from other, for example, inner layers of the radiation source, can occur

$$
-V \cdot \partial \mu / \partial x \approx V \cdot \mu / l>0
$$

where $-V \cdot \nabla \mu \approx V \cdot \mu \cdot l^{-1}$ it is responsible for convective transfer of inversion with speed $V$ from denser underlying source layers [10].

In these works, it was shown that the inversion flux into the region of the active medium can lead to a change in the relaxation nature of oscillations to periodic. In this case, one can observe the appearance of characteristic sawtooth periodic pulses of induced radiation against the background of the average radiation flux. It is important to note that such pulses occur only under equilibrium conditions $I_{0}=0$ and also in the case of proximity of the generation thresholds (5) and (6), and their repetition rate depends on the quantum absorption decrement $\delta_{D}$ and the rate of change of the inversion due to its transfer. In the discussed models, for convenience of description, the field quanta were divided by origin: $N_{k}^{(i n c o h)}$ - the density of the number of quanta of the incoherent radiation field and the density of the number of quanta of the field of induced radiation $N_{k}^{(c o h)}$. The equations describing the generation of sawtooth pulses of induced radiation in a continuous medium can be written in the form [10]

$$
\begin{aligned}
& \partial \mathrm{N}_{c} / \partial T=\mathrm{M} \cdot \mathrm{N}_{c}-\theta \cdot \mathrm{N}_{c}, \\
& \partial \mathrm{M} / \partial T=K \cdot \mathrm{M}-2 \mathrm{M} \cdot \mathrm{N}_{c}+I_{0},
\end{aligned}
$$

where $\mathrm{M}=\mu / \mu_{0}$, is the relative population inversion, $T=w_{21} \cdot \mu_{0} \cdot t, \mathrm{~N}_{c}=N_{k}^{(a b)} / \mu_{0}^{-}$is the relative number of quanta of induced radiation $\theta=\delta_{D} / w_{21} \mu_{0}, K=V / w_{21} \mu_{0} l, N_{0}=N / 2 \mu_{0}^{2}$.

The change in the relative number of quanta of spontaneous emission $\mathrm{N}_{\text {inc }}=N_{k}^{(\text {incoh })} / \mu_{0}$ is described by the equation

$$
\partial \mathrm{N}_{\text {inc }} / \partial T=\left(N_{0} / 2\right)-\theta \cdot \mathbf{N}_{\text {inc }} .
$$

When $I_{0}>0$, when the collisional excitation is large, the induced radiation is monotonic in nature, in the case of $I_{0}<0$ you can see that there is no induced radiation. That is, the generation of periodic pulses reveals itself only under conditions of equilibrium of the processes of collisional excitation by free electrons of the main gas of active atoms and their radiative relaxation mainly due to spontaneous emission $I_{0}=0$ [10]. In this case, the integrated radiation intensity during the appearance of a pulse can increase several times. It should be noted that the authors of [10] noticed the considered phenomenon only under the condition of equilibrium $I_{0}=0$ and also in the case of proximity of the generation thresholds (5) and (6).

\section{DESCRIPTION OF THE PULSE GENERATION PROCESS USING THE QUASICLASSIC THEORY}

With a higher field intensity or with a significant inversion, the induced radiation in a bounded waveguide system should be described by a semiclassical theory [11], where the medium is described quantum mechanically and the electric field in the classical representation. The nature of the process depends on the ratio of the line width of the wave packet to the Rabi frequency, which determines the probabilities of induced radiation or absorption of field quanta $[12,13]$ in each region of the waveguide along its length. With a significant population inversion or in strong fields, the line width can be neglected. For small population inversions and for low electric field intensities, when the Rabi frequency is less than the line width of the wave packet, the behavior of a two-level system is similar to the description of the process presented in [1].

Let us consider a one-dimensional model for perturbations of the electric field, polarization, and population inversion slowly varying with time, which describe the excitation of electromagnetic waves in a two-level active medium, the equations of which can be represented as [11]

$$
\frac{\partial^{2} E}{\partial t^{2}}+\delta_{D} \frac{\partial E}{\partial t}-c^{2} \frac{\partial^{2} E}{\partial x^{2}}=-4 \pi \frac{\partial^{2} P}{\partial t^{2}}
$$




$$
\begin{gathered}
\frac{\partial^{2} P}{\partial t^{2}}+\gamma_{12} \frac{\partial P}{\partial t}+\omega^{2} \cdot P=-\frac{2 \omega\left|d_{a b}\right|^{2}}{\hbar} \mu E \\
\frac{\partial \mu}{\partial t}=\frac{2}{\hbar \omega}<E \frac{\partial P}{\partial t}>
\end{gathered}
$$

where the transition frequency $\omega$ between the levels corresponds to the field frequency, we neglect the relaxation of the inversion due to external reasons, $\delta_{D}$ is the decrement of field absorption in the medium, and $d_{21}$ is the matrix element of the dipole moment (more precisely, its projection on the direction of the electric field), $\mu=\left(n_{2}-n_{1}\right)$ - the population difference per unit volume, $n_{2}$ and $n_{1}$ - levels populations in the absence of a field, $\gamma_{12}$ - the width of the spectral line, $N=\left(n_{1}+n_{2}\right)$ is the density of the dipoles of the active medium. Fields are represented as $E=\left[E(t) \cdot \exp \{-i \omega t\}+E^{*}(t) \cdot \exp \{i \omega t\}\right]$ and $P=\left[P(t) \cdot \exp \{-i \omega t\}+P^{*}(t) \cdot \exp \{i \omega t\}\right]$.

Wherein $<E^{2}>=2|E(t)|^{2}$. The number of field quanta is then determined as $<E^{2}>/ 4 \pi \hbar \omega=2|E|^{2} / 4 \pi \hbar \omega=N_{c}$. Spontaneous emission is absent in this representation, but as shown above, it is not difficult to take into account, for example, using equation (12). For slowly varying amplitudes, the equations

$$
\begin{gathered}
\frac{\partial \mathrm{E}}{\partial \tau}+\Theta \cdot \mathrm{E}=\frac{i}{2} \mathrm{P}, \\
\frac{\partial \mathrm{P}}{\partial \tau}+\Gamma_{12} \mathrm{P}=-i M \mathrm{E}, \\
\frac{\partial M}{\partial \tau}=K \cdot M+\frac{i}{2}[\mathrm{EP} *-\mathrm{E} * \mathrm{P}],
\end{gathered}
$$

the notation is used here $\mu / \mu_{0}=M, K=\left(V / \Omega_{0} l\right)$, and we immediately note that changes in population inversions will be determined by the choice $\mu_{0}$ and initial conditions, $\Omega_{0}=\left|d_{a b}\right| \cdot\left|E_{0}\right| / \hbar=\left|d_{a b}\right| \cdot\left[4 \pi \omega \cdot \mu_{0} / \hbar\right]^{1 / 2}$ is the Rabi frequency corresponding to the value of the electric field amplitude $\left|E_{0}\right|=\left[4 \pi \hbar \omega \mu_{0}\right]^{1 / 2} \mathrm{E}=\frac{E(t)}{\left[4 \pi \hbar \omega \mu_{0}\right]^{1 / 2}}, \mathrm{P}=\frac{P(t)}{\left[4 \pi \hbar \omega \mu_{0}\right]^{1 / 2}} \cdot \frac{4 \pi \omega}{\Omega_{0}}$, $\tau=\Omega_{0} t, \Gamma_{12}=\gamma_{12} / \Omega_{0}, \Theta=\delta / \Omega_{0}$.

At low field intensities or a large line width $\Gamma_{12}=\gamma_{12} / \Omega_{0}>>1$, using the notation $\mathrm{N}_{c}=<E^{2}>_{c} / 4 \pi \hbar \omega \mu_{0}$, $M=\mathrm{M}=\mu / \mu_{0}, \tau_{1}=\Omega_{0}^{2} t / \gamma_{12}, K_{1}=\left(V / \Omega_{0} l\right)\left(\gamma_{12} / \Omega_{0}\right), \Theta_{1}=\left(\delta_{D} / \Omega_{0}\right) \cdot\left(\gamma_{12} / \Omega_{0}\right)$, we obtain the system of equations $(10)-$ (11) when the equilibrium condition is satisfied $I_{0}=0$.

That is, it is easy to see that the previous description (10 - (11) corresponds to the equality, whence it follows. You can make the system of equations one-parameter by dividing the right and left parts by and passing to the values, write the equations in the form

$$
\begin{aligned}
& \frac{\partial M}{\partial \tau_{1}}=K_{1} \cdot M-2 M \cdot N_{c}, \\
& \frac{\partial N}{\partial \tau_{1}}=M \cdot N_{c}-2 \Theta_{1} N_{c},
\end{aligned}
$$

That is, it is easy to see that the previous description $(10-11)$ corresponds to the equality $T=\tau_{1}$, whence it follows $w_{21}=\Omega_{0}^{2} / \mu_{0} \cdot \gamma_{12}$. You can make the system of equations one-parameter by dividing the right and left parts by $\Theta_{1}^{2}$ and passing to the value $N_{c}=\Theta_{1} \cdot N_{2}, \quad M=\Theta_{1} \cdot M_{2}, \quad \tau_{2}=\Theta_{1} \cdot \tau_{1}, \quad K_{1}=\Theta_{1} \cdot K_{2}$, write the equations in the form

$$
\begin{gathered}
\frac{\partial M_{2}}{\partial \tau_{2}}=K_{2} \cdot M_{2}-2 M_{2} \cdot N_{2} \\
\frac{\partial N_{2}}{\partial \tau_{2}}=M_{2} \cdot N_{2}-2 N_{2}
\end{gathered}
$$


where $\tau_{2}=\Theta_{1} \cdot \tau_{1}=\delta_{D} t, M_{2}=\frac{\mu}{\mu_{0}} \frac{\Omega_{0}{ }^{2}}{\delta \cdot \gamma_{12}}, N_{2}=\frac{<E^{2}>}{4 \pi \hbar \omega} \frac{\Omega_{0}{ }^{2}}{\delta \cdot \gamma_{12}}$.

These equations describe the generation of induced radiation, with the number of quanta per unit volume $N_{c}=N_{k}^{(c o h)}$, which is the periodic pulses with some constant component.

In addition, there is a spontaneous incoherent component of the same source, the number of quanta of which is equal $N_{\text {inc }}=N_{k}^{(i n c o h)} / \mu_{0}$, described, for example, by equation (12). A significant part of the radiation of a quantum source is induced radiation, which is almost monochromatic. However, if the quantum source is surrounded by a fairly extended atmosphere, due to multiple scattering, as noted in [8], the radiation characteristics will approach the radiation characteristics of an absolute black body. The total number of radiation quanta per unit volume is equal to $N=N_{i n c}+N_{c}$, and in spontaneous emission, all types of radiation should be taken into account, and not just the radiation of a quantum source. It is important to note that despite an extremely small population inversion, the intensity of the induced radiation may well exceed the spontaneous intensity.

System (21-22) has a singular point $\left(2, K_{2} / 2\right)$ and a stationary solution: $M_{2}=2, N_{2}=K_{2} / 2$. In the case of small deviations $M_{2}, \quad N_{2}$ from the singular point, the system can be linearized and the equation for the phase trajectory obtained: $K_{2}\left(M_{2}-2\right)^{2}+8\left(N_{2}-K_{2} / 2\right)^{2}=$ Const. The phase trajectory turns out to be a closed line, which indicates the presence of stable periodic solutions.

In Figure 1-3 shows the time dependences $M_{2}, N_{2}$ and phase trajectories for different cases of removal from the critical point at $K_{2}=20$. The initial values $M_{2}$ for were set constant $M_{2}(0)=2$, the choice of the curve was controlled by removing the initial value $N_{2}(0)$ from its critical value equal to 10 .
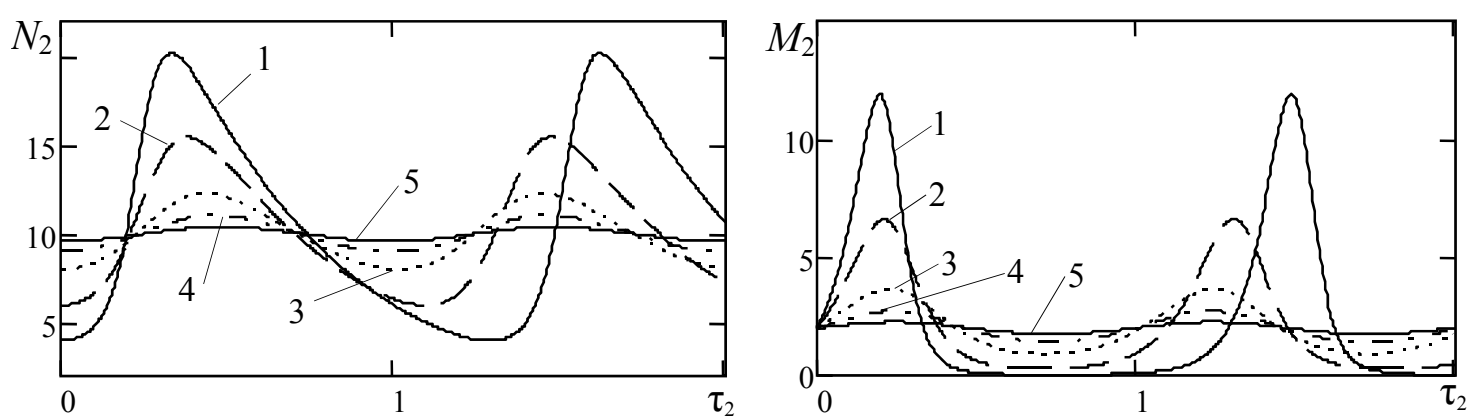

Figure 1. a). The behavior of the relative magnitude of the density of quanta as a function of time $\tau_{2}$ b) The behavior of the relative density of the inversion of populations as a function of time $\tau_{2}$, for $1-N_{2}(0)=4 ; 2-N_{2}(0)=6 ; 3-N_{2}(0)=8 ; 4-N_{2}(0)=9 ; 5-$ $N_{2}(0)=9.6$.

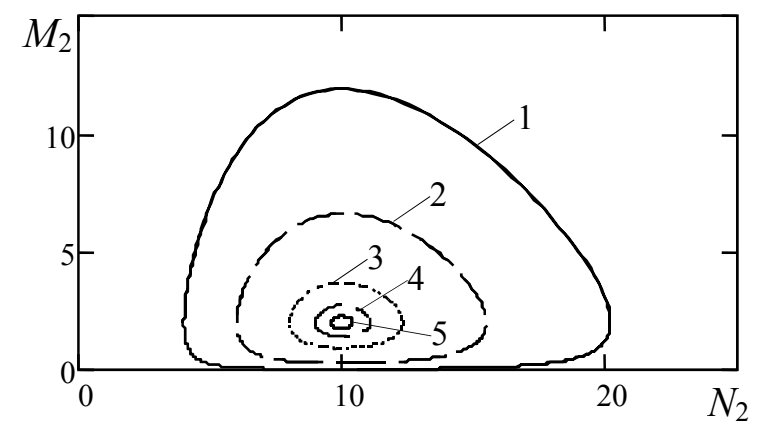

Figure 2. Phase diagrams for the system of equations (21) - (22) when choosing the initial conditions in the form $1-N_{2}(0)=4 ; 2$ -

$$
N_{2}(0)=6 ; 3-N_{2}(0)=8 ; 4-N_{2}(0)=9 ; 5-N_{2}(0)=9.6 \text {. }
$$

For clarity, Table 1 shows the minimum number of quanta $N_{2 \min }$ (constant component in the induced radiation), the maximum number of quanta $N_{2 \max }$, the average value of the number of quanta $N_{2 a v}$, the amplitude of oscillations $N_{2 \max }-N_{2 \min }$, and the period of oscillations $T_{2}$. It should be noted that the average value of the relative number of quanta $N_{2 a v}$ depends only on the choice of the position of the center of the diagram - its critical value $K_{2} / 2$.

The graph of the number of quanta $N_{2}$ changes has the form of a sinusoid for phase trajectories near the critical point (calculation 4 and 5). For phase trajectories far from the critical point (calculations 1, 2), the change graph $N_{2}$ 
takes the form of a saw: a sharp increase and a slow decrease. Such behavior is characteristic of the Cepheid luminosity, where fusion has reached its ultimate element - iron: significant sawtooth fluctuations in the luminosity of the Cephei delta and small sinusoidal oscillations of the North Star.

The results of the solution of equations (21)-(22)

Table 1.

\begin{tabular}{|c|c|c|c|c|c|}
\hline N data & $N_{2 \min }$ & $N_{2 \max }$ & $N_{2 a v}$ & $N_{2 \max }-N_{2 \min }$ & $T_{2}$ \\
\hline 1 & 4 & 20,188 & 10 & 16,188 & 1,289 \\
\hline 2 & 6 & 15,474 & 10 & 9,474 & 1,0964 \\
\hline 3 & 8 & 12,308 & 10 & 4,308 & 1,0147 \\
\hline 4 & 9 & 11,071 & 10 & 2,071 & 0,9984 \\
\hline 5 & 9,635 & 10,374 & 10 & 0,739 & 0,9941 \\
\hline
\end{tabular}

\section{ABOUT POSSIBLE APPLICABILITY OF THE MODEL}

Indeed, such a generation may well occur in cosmic conditions, where their radiation is generated in the photosphere of stars. The presence of pulsations is possible if the conditions are met in the presence of convection, which ensures the delivery of inverted atoms of the active substance from the dense underlying layers, that is $-v \cdot \partial \mu / \partial x \approx v \cdot \mu / l$, convection should be quite intense $\left(v / l \cdot w_{21}\right)>\mu_{T H 2}$. We show that the above-considered model of generation of pulses of induced radiation can be useful for describing a periodic change in the luminosity of Cepheid stars.

As noted above, $N_{2}$ can describe the generation of induced radiation, for example, in the photosphere of stars, which is a pulse with a certain constant component. In addition, there is a spontaneous incoherent component of the same source. To this radiation, it is necessary to attach the constant radiation of the rest of the heated material of the star, i.e. the total emission of the star takes the form

$$
N(\tau)=N_{b}+N_{2}(\tau)
$$

The value of the constant component $N_{b}$ (the spontaneous incoherent component of a quantum source and the constant radiation of the rest of the warmed matter of the star) must be added to $N_{2}$. This addition can be estimated by knowing the relationship between the maximum and minimum luminosity of a star $k=\left(N_{b}+N_{2 \max }\right) /\left(N_{b}+N_{2 \min }\right)$, on the other hand, the ratio of the maximum and minimum luminosities of a star is $k=L_{1} / L_{2}=10^{0,4\left(m_{2}-m_{1}\right)}$ [14], here $m_{1}$ is the apparent magnitude at the maximum luminosity of the star, $m_{2}-$ at the minimum luminosity. Below we will focus on the values of the apparent magnitude obtained from observations. Using the known apparent magnitude $m$, knowing the distance to the star $d$ in parsec, we can calculate the luminosity [14]:

$$
m=M_{l \odot}+5 \lg (d / 10)-2.5 \lg (L) .
$$

To compare the luminosities of stars with each other, the absolute magnitude (apparent magnitude from a distance of 10 parsecs) $M_{l}=m-5 \lg \left(d / d_{0}\right), d_{0}=10$ is used, $d$ here is the distance in parsecs to the star, $d=273$ for the Cephei delta and $d=133$ for the North Star. Then the luminosity of the star in units of the luminosity of the Sun is equal to $L=10^{0,4\left(M_{\odot}^{-M)}\right.} L_{\odot}, \quad L_{\odot}=1$, where $M_{l \odot}=4.77$ is the absolute magnitude of the Sun. To obtain the dependence of the luminosity of the star on time $L(\tau)$, we multiply (23) by the coefficient A, i.e.

$$
L(\tau)=A \cdot N(\tau)=A \cdot\left[N_{b}+N_{2}(\tau)\right]
$$

Table 2 shows the calculation results for the Cepheus delta and the North Star. For this, the values of Table 1 are taken from the first and fifth rows.

The calculation results for the Cepheus delta and the North Star

\begin{tabular}{|c|c|c|c|c|c|c|c|c|c|c|}
\hline Stars & $m_{1}$ & $m_{2}$ & $k$ & $N_{2 \min }$ & $N_{2 \max }$ & $N_{2 a v}$ & $N_{b}$ & $A$ & $L_{1}$ & $L_{2}$ \\
\hline Cephei delta & 3.48 & 4.37 & 2.27 & 4 & 20,188 & 10 & 8.748 & 84.507 & 2445.3 & 1077.3 \\
\hline North Star & 2.092 & 2.125 & 1.031 & 9.635 & 10,374 & 10 & 14.315 & 84.412 & 2084 & 2021.6 \\
\hline
\end{tabular}


You can make sure that the average value $\bar{L}$ is determined by the formula

$$
\bar{L}=A \cdot\left(N_{2 a v}+N_{b}\right) \text {. }
$$

Fig. $4 \mathrm{a}$ and Fig. $4 \mathrm{~b}$ show the time dependences of the number of quanta and the corresponding luminosity of the Cephei delta and the North Star. The bottom curve is the number of quanta of induced radiation. The upper curve takes into account the constant component of spontaneous emission due to other elements of the radiation source, in addition to the quantum system.

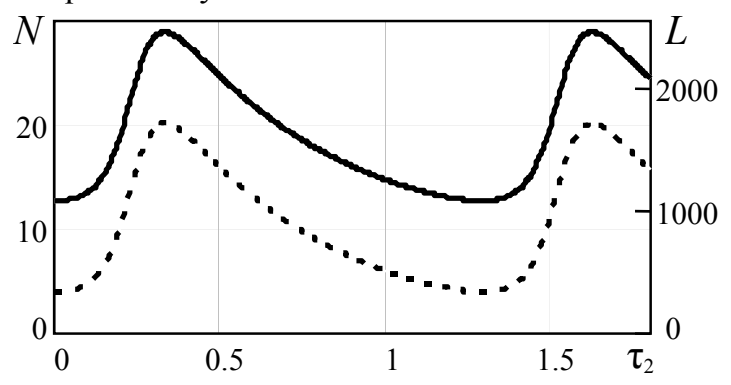

a

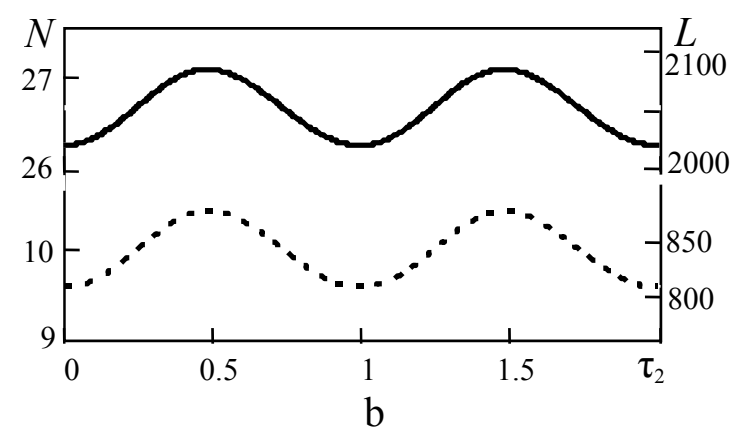

b

Figure 4. Time dependences of the relative number of quanta (left scale) and the corresponding luminosity (right scale) of the Cephei delta (a) and the North Star (b).

The lower curve on each fragment represents the number of quanta of induced radiation. The upper curve takes into account the constant component of spontaneous emission due to other elements of the radiation source, in addition to the quantum system.

Fig. 5 and Fig. 6 below show the change in the stellar magnitude of the star of the Cepheus delta [15] and the North Star with time [16]. The ordinate shows the values of the apparent magnitude, while the abscissa shows time in fractions of the period of change in the brightness of the star.

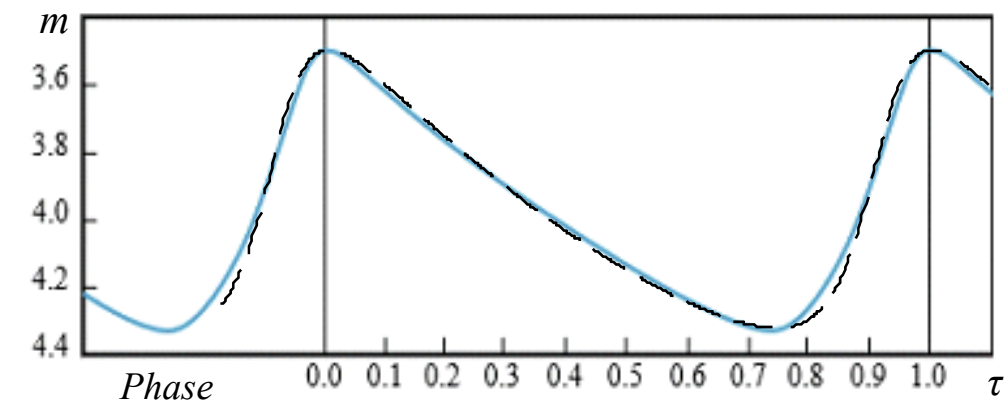

Figure 5. The change in the stellar magnitude of the star of the Cepheus delta with time. (solid curve received in the 1930s N.F. Florey using a visual photometer) see, for example, [17] and the solution of equations of system (21) - (22) in the same variables when choosing the level of spontaneous emission and scales (dashed line).

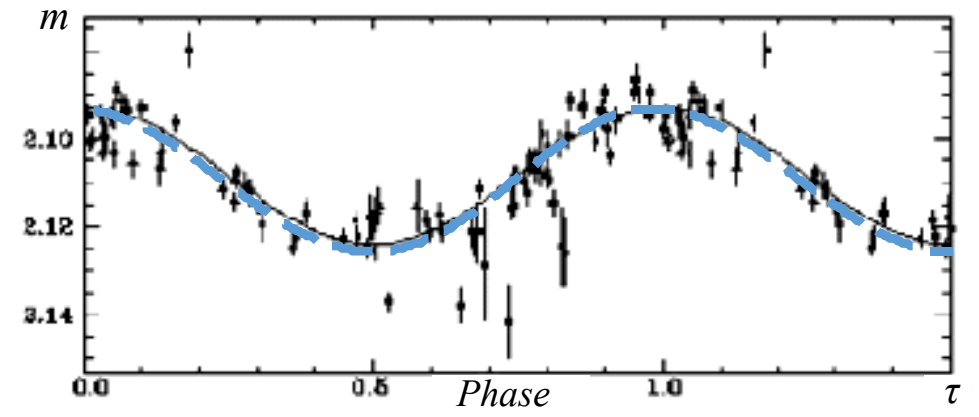

Figure 6. The change in the magnitude of the North Star with time. (solid curve) and the solution of the equations of system (20) -

(21) in the same variables when choosing the level of spontaneous emission and scales (dashed line).

\section{CONCLUSIONS}

The state of a gas radiation source close to equilibrium under collisional excitation by free electrons of the main gas of active atoms and their radiative relaxation due mainly to spontaneous emission was considered [10]. In such a medium, for a two-level system, when the population inversion is much less than the total number of states, there are conditions for the generation of pulses of induced radiation.

Moreover, the intensity of such pulses is comparable with the intensity of spontaneous emission of the system. It was shown earlier that during convection from deeper hot layers, which supports (is the source) the population 
inversion of the active system, it is possible to generate periodic pulses of induced radiation, the intensity of which is comparable to or greater than the intensity of the background spontaneous radiation of the source [10]. With a sufficient thickness of the surface layers due to the effects of scattering of radiation in them, the emission spectrum of a completely black body may well form there [8].

Pulse generation near a previously detected new threshold of induced radiation [10] under the conditions of such convection can lead to a periodic change in the radiation intensity of the source as a whole. This threshold is due to competition between spontaneous and induced radiation, which weaken the population inversion and is determined by the equality of the square of the population inversion to the total number of states. A consideration of the generation of pulses of induced radiation in the present work is carried out both using Einstein's balanced equations and on the basis of a semiclassical description for small population inversions and at low levels of electric field intensity, when the Rabi frequency is less than the width of the radiation line.

It is shown in the paper that the description of the induced radiation process reduces to a one-parameter system of two equations (21) - (22). Periodic solutions are represented by closed trajectories on the phase plane (relative density of quanta, relative density of population inversion). A similar layer with an active medium, which can be described by a quantum two-level system located near equilibrium, can exist in stars and is most likely localized in the photosphere. If there is significant convection in the star's atmosphere, conditions can be realized for generating pulses of induced radiation. It turns out that one can see the similarity of the obtained solutions with the well-known observations of changes in the luminosity of Cepheid stars (Cepheus delta and the North Star). Moreover, the ratio of periods of change in luminosity is (according to table 1.) also similar (accurate to $2.5 \%$ ). It is important to note that the solutions of equations (21) - (22) for these two cases are on the same diagram in Fig. 3, which corresponds to one type of object. As well as small amplitude Cepheids (DCEPS) of the North Star type, they belong to the class of classical Cepheids, the brightest representative of which is the Cepheus delta.

\section{ACKNOWLEDGEMENTS}

The authors are sincerely grateful to prof. Hilding Neilson for constructive comments and prof. V. A. Buts for useful discussions and attention to the work.

\section{ORCID IDs}

(DVolodymyr M. Kuklin, http://orcid.org/0000-0002-0310-1582; Eugen V. Poklonskiy, https://orcid.org/0000-0001-5682-6694

\section{REFERENCES}

[1] A. Einstein, Mitteilungen, D. Phys. Ges. Zürich 18, 47-62 (1916); Phys. Z. 18, 121-128 (1917); UFN 86 (3), $371-411$ (1965), https://doi.org/10.3367/UFNr.0086.196507b.0371, in https://ufn.ru/ru/articles/1965/7/b/, (in Russian).

[2] R. Ladenburg, Rev. Mod. Phys. 4, 243-260 (1933); UFN $14 \quad$ (6), 721-741 (1934), https://doi.org/10.3367/UFNr.0014.193406b.0721, in https://ufn.ru/ru/articles/1934/6/b/, (in Russian)

[3] L.D. Landau, and E.M. Livshits, Electrodynamics of continuous media. (Moscow, GIFLML, 1959), pp. 532, (in Russian).

[4] V.L. Ginzburg, UFN, 140 (4), 687-698 (1983), (in Russian)

[5] Ch.H. Townes, Science, 149 (3686), 831-841 (1965), https://doi.org/10.1126/science.149.3686.831; UFN. 88 (3), 461-483 (1966), (in Russian).

[6] A.G. Zagorodny, and V.M. Kuklin, in: High-power pulsed electrophysics. International conference XIV Khariton's topical scientific readings. Digest of technical papers (Sarov, 2013), pp. 38-43, (in Russian)

[7] A.V. Kirichok, V.M. Kuklin, A.V. Mischin, A.V. Pryjmak, and A.G. Zagorodny, VANT. Ser.: Plasma Electronics and New Methods of Acceleration, 4 (77), 267-271 (2013).

[8] S.B. Pickelner, Atmospheres of stars, (Physics of Space, 1986), http://www.astronet.ru/db/msg/1179555, (in Russian)

[9] C.L. Statz, and G. DeMars, Quantum Electronics, (N.Y., Columbia Univ. Press, 1960), pp. 530.

[10] A.V. Kirichok, V.M. Kuklin, and A.G. Zagorodny, VANT. Ser.: Plasma Electronics and New Methods of Acceleration, 4 (80), 9-11 (2015), https://arxiv.org/pdf/1610.04628v1.

[11] P.S. Landa, Self-oscillations in distributed systems, (Moscow, Nauka, 1983), pp. 320, in Russian

[12] A.S. Davydov, Quantum mechanics, (Fizmatgiz, Moscow, 1963), pp. 748, in Russian

[13] L. Allen, J. Eberly, Optical resonance and two-level atoms. (New York, Wiley-Interscience, 1975), pp. 222.

[14] A.S. Rastorguev, Lectures on Galactic Astronomy, in http://www.astronet.ru/db/msg/1228262, in Russian

[15] J. Kaler, Stars and stars of the week, (University of Illinois), in http://stars.astro.illinois.edu/sow/deltacep.html

[16] J. Kaler, Stars and stars of the week, (University of Illinois), in http://stars.astro.illinois.edu/sow/polaris.html

[17] N.N. Samus, and O.V. Durlevich, GCVS - General Catalog of Variable Stars, (Institute of Astronomy of Russian Academy of Sciences, Sternberg State Astronomical Institute of the Moscow State University), in: http://heasarc.gsfc.nasa.gov/W3Browse/all/gcvs.html.

\section{ПРО ПЕРІОДИЧНІ ЗМІНИ СВІТНОСТІ КОСМІЧНИХ ДЖЕРЕЛ 3 АКТИВНИМ СЕРЕДОВИЩЕМ}

\section{В.В. Костенко, В.М. Куклін, С.В. Поклонський}

Харківський національний університет імені В.Н. Каразіна, Харків, Украйна пл. Свободи 4, Харків, Украӥна, 61022

Розглянуто наявність в гарячому джерелі випромінювання внутрішнього шару з активним середовищем, що знаходиться поблизу рівноваги і представлено квантовою дворівневою системою, населеністі верхнього і нижнього рівнів якої приблизно однакові. Показано, що при конвекції з більш глибоких гарячих шарів, яка підтримує інверсію населеністі активної системи, можлива генерація імпульсів індукованого випромінювання, інтенсивність яких порівнянна або 
перевершує інтенсивність фонового спонтанного випромінювання джерела. При достатній товщині поверхневих шарів за рахунок ефектів розсіювання в них, там цілком може сформуватися спектр випромінювання абсолютно чорного тіла. Генерація імпульсів поблизу виявленого раніше нового порога індукованого випромінювання здатна привести до періодичної зміни інтенсивності випромінювання джерела в цілому. Цей поріг визначається рівністю квадрату інверсії населеності повному числу станів. Розгляд генерації імпульсів індукованого випромінювання проводиться як на основі балансних рівнянь, так і за допомогою напівкласичного опису при невеликих значеннях інверсії населеності і при низьких рівнях інтенсивності електричного поля, коли частота Рабі менше ширини лінії. Опис процесу індукованого випромінювання зводиться до однопараметричної системі рівнянь. Періодичні рішення представлені замкнутими траєкторіями на фазової площині (відносна щільність квантів, відносна щільність інверсії населеністі). Подібний шар 3 активним середовищем в вигляді квантової дворівневої системи може існувати в зірках і швидше за все локалізован в області фотосфери. При наявності в атмосфері зірки значною конвекції можуть бути реалізовані умови для генерації імпульсів індукованого випромінювання. Виявляється, що можна побачити подібність отриманих рішень 3 відомими спостереженнями змін світності зірок-цефеїд (дельти Цефея і Полярної зірки).

КЛЮЧОВІ СЛОВА: генерація імпульсів індукованого випромінювання, конвективне джерело інверсії населеністі, періодична зміна світності зірок-цефеїд.

\section{О ПЕРИОДИЧЕСКОМ ИЗМЕНЕНИИ СВЕТИМОСТИ КОСМИЧЕСКИХ ИСТОЧНИКОВ С АКТИВНОЙ СРЕДОЙ \\ В.В. Костенко, В.М. Куклин, Е.В. Поклонский \\ Харьковский наииональный университет имени В.Н. Каразина, Харьков, Украина пл. Свободы 4, Харьков, Украина, 61022}

Рассмотрено наличие в горячем источнике излучения внутреннего слоя с активной средой, которую можно описать находящейся вблизи равновесия квантовой двухуровневой системой, населенность верхнего и нижнего уровней которой примерно равна. Показано, что при конвекции из более глубоких горячих слоев, которая поддерживает инверсию населенностей активной системы, возможна генерация импульсов индуцированного излучения, интенсивность которых сравнима или превосходит интенсивность фонового спонтанного излучения источника. При достаточной толщине поверхностных слоев за счет эффектов рассеяния в них излучения, там вполне может сформироваться спектр излучения абсолютно черного тела. Генерация импульсов вблизи обнаруженного ранее нового порога индуцированного излучения способна привести к периодическому изменению интенсивности излучения источника в целом. Этот порог определяется равенством квадрата инверсии населенностей полному числу состояний. Рассмотрение генерации импульсов индуцированного излучения проводится как в представлении Эйнштейна, на основе балансных уравнений, так и с помощью полуклассического описания при небольших значениях инверсии населенностей и при низких уровнях интенсивности электрического поля, когда частота Раби меньше ширины линии. Описание процесса индуцированного излучения сводится к однопараметрической системе уравнений. Периодические решения представлены замкнутыми траекториями на фазовой плоскости (относительная плотность квантов, относительная плотность инверсии населенностей). Подобный слой с активной средой, которую можно описать находящейся вблизи равновесия квантовой двухуровневой системой может существовать в звездах и скорее всего локализован в области фотосферы. При наличии в атмосфере звезды значительной конвекции могут быть реализованы условия для генерации импульсов индуцированного излучения. Оказывается, что можно увидеть подобие полученных решений с известными наблюдениями изменениями светимости звезд-цефеид (дельты Цефея и Полярной звезды).

КЛЮЧЕВЫЕ СЛОВА: генерация импульсов индуцированного излучения, конвективный источник инверсии населенностей, периодическое изменение светимости звезд-цефеид. 